\title{
Mating patterns and demography in the tristylous daffodil Narcissus triandrus
}

\author{
KA Hodgins and SCH Barrett \\ Department of Botany, University of Toronto, 25 Willcocks Street, Toronto, ON, Canada M5S 3B2
}

\begin{abstract}
Mating patterns in plant populations are influenced by interactions between reproductive traits and ecological conditions, both factors that are likely to vary geographically. Narcissus triandrus, a wide-ranging heterostylous herb, exhibits populations with either two (dimorphic) or three (trimorphic) style morphs and displays substantial geographical variation in demographic attributes and floral morphology. Here, we investigate this variation to determine if demography, morphology, and mating system differ between the two sexual systems. Our surveys in Portugal and NW Spain indicated that dimorphic populations were less dense, of smaller size, and had larger plants and flowers compared to trimorphic populations. Outcrossing rates estimated using allozyme markers revealed similar outcrossing rates in dimorphic and trimorphic populations $\left(t_{\mathrm{m}}\right.$ dimorphic $=0.759$; $t_{\mathrm{m}}$ trimorphic $\left.=0.710\right)$. All populations experienced significant inbreeding in progeny (mean $F=0.143$ ). In contrast,
\end{abstract}

parental estimates of inbreeding were not significantly different from zero (mean $F=0.062$ ), implying that few inbred offspring survive to reproductive maturity due to inbreeding depression. Although the majority of inbreeding results from selfing, significant levels of biparental inbreeding were also detected in eight of the nine populations (mean $\left.s_{s}-s_{m}=0.081\right)$. Density was negatively associated with levels of selfing but positively associated with biparental inbreeding. Population size was positively associated with outcrossing but not biparental inbreeding. There were no consistent differences among the style morphs in outcrossing or biparental inbreeding indicating that the maintenance of trimorphism vs dimorphism is unlikely to be associated with inbreeding of maternal parents.

Heredity (2006) 96, 262-270. doi:10.1038/sj.hdy.6800792; published online 1 February 2006

Keywords: biparental inbreeding; demography; Narcissus triandrus; mating system; outcrossing rates; tristyly

\section{Introduction}

Mating patterns in flowering plants are products of complex interactions between reproductive traits and the ecology of populations (Lloyd, 1980; Holsinger, 1996). An important aspect of mating is the amount of selffertilization experienced by individuals. Selfing has important genetic consequences, including its influence on the strength of inbreeding depression (Charlesworth and Charlesworth, 1987) and the partitioning of genetic variation within and among populations (Hamrick and Godt, 1989). In species that lack strong self-incompatibility, selfing may increase when insufficient quantities of outcrossed pollen are deposited on stigmas. In animalpollinated plants, spatial isolation and small population size generally act to reduce the frequency of pollinator visitation (Sih and Baltus, 1987; Agren, 1996). Thus, under such conditions selfing is predicted to increase (Moeller and Geber, 2005). Indeed, several studies have investigated the association between outcrossing rates and density or population size (vanTreuren et al, 1993; Raijmann et al, 1994; Routley et al, 1999; Lu, 2000; Barrett et al, 2004a; Zoro Bi et al, 2005). However, results from these studies have been mixed indicating that the

Correspondence: KA Hodgins, Department of Botany, University of Toronto, 25 Willcocks Street, Toronto, ON, Canada M5S 3B2.

E-mail: hodgins@botany.utoronto.ca

Received 8 July 2005; accepted 15 November 2005; published online 1 February 2006 ecology of selfing rates warrants further investigation, particularly in wide-ranging species exposed to contrasting environmental conditions.

The demographic characteristics of populations, through their impact on pollinator behaviour, might also be expected to influence the intensity of biparental inbreeding. Observations of spatially restricted pollen and seed dispersal in plants have led to the prediction that populations will often be genetically subdivided at a local scale (Wright, 1943; Turner et al, 1982; Heywood, 1991; Kalisz et al, 2001). Pollinator foraging distances are generally negatively correlated with density, such that at high-density pollen dispersal distances are shorter than at low density (Levin and Kerster, 1969b; Kameyama et al, 2002). Thus, in dense populations, pollinator behaviour in combination with genetic subdivision is likely to result in increased biparental inbreeding with potential consequences for plant fitness.

Narcissus triandrus is a wide-ranging, bee-pollinated herb with populations that vary in demographic and morphological characters likely to influence mating patterns. This species possesses a tristylous sexual system and a particular focus of our study was to examine how mating patterns influence the maintenance of this genetic polymorphism. In tristylous populations there are three floral morphs that differ reciprocally in the placement of their anthers and stigmas (long-, midand short-styled, hereafter referred to as L-, M- and S-morphs). The style morphs in most tristylous species possess a heteromorphic incompatibility system that 
prevents selfing and intra-morph mating. The resulting disassortative mating generally gives rise to an isoplethic equilibrium of morph ratios (Fisher, 1941, 1944; Charlesworth, 1979; Heuch, 1979; Barrett, 1993). However, some tristylous species lack this type of incompatibility providing opportunities for selfing and intra-morph mating (Barrett and Cruzan, 1994). Increased selfing rates have been implicated in causing deviations from isoplethy and the breakdown of tristyly via the loss or fixation of the morph with the highest selfing rate (Charlesworth, 1979).

$N$. triandrus lacks heteromorphic incompatibility and instead possesses a late-acting self-incompatibility system that is often weakly expressed (Barrett et al, 1997; Sage et al, 1999). Population morph ratios usually deviate strongly from 1:1:1 (isoplethy) (Fernandes, 1965; Barrett et al, 1997). Based on large-scale surveys conducted in the Iberian Peninsula (Barrett et al, 2004b), three distinctive patterns characterize populations: (1) most populations are L-morph biased; (2) there is a negative association between the frequencies of the L- and M-morphs; and (3) some populations lack the M-morph and are thus dimorphic. Only dimorphic populations occur in the north-west part of the range whereas in central Portugal dimorphic and trimorphic populations are often found in close geographic proximity. Preliminary observations indicate that variation in the sexual system of $N$. triandrus is associated with geographical variation in floral morphology (see Barrett et al, 2004b) and possibly also demographic features of populations including their size and density. Thus, $N$. triandrus provides an opportunity to investigate the influence of demography and reproductive morphology on mating patterns with potential relevance to the maintenance of stylar trimorphism vs dimorphism.

Here, we address three specific questions concerning the relations between mating patterns, floral morphology and demography in N. triandrus. (1) Are there differences between dimorphic and trimorphic populations in demographic and morphological characteristics? (2) Do outcrossing rates and biparental inbreeding vary significantly among populations that differ in demography and sexual system? (3) Are there morph-specific differences in the rates of self-fertilization and biparental inbreeding? We discuss the implication of our results for the maintenance of sexual-system polymorphism in $N$. triandrus and factors responsible for the loss of the M-morph from trimorphic populations.

\section{Materials and methods}

\section{Study species}

$N$. triandrus L. (Amaryllidaceae) is a diminutive perennial geophyte, common in the central and northern parts of the Iberian Peninsula. Populations start flowering in late February at the southern margin of the range in Andalucía and continue until mid May at higher elevations in central and northern Spain and Portugal. Flowering plants produce a single stem with 1-9 (mean 1.6) pale yellow to cream pendulous flowers that last up to 14 days. Solitary bees, particularly Anthophora pilipes Fabr., are the primary pollinators, although in the cooler Atlantic zone in northern Spain and Portugal Bombus spp. visit flowers. Several intra-specific taxa have been described in N. triandrus (Blanchard, 1990) but here we focus exclusively on the widespread $N$. triandrus var. triandrus as this taxon displays the greatest morphfrequency variation including all dimorphic populations reported for the species (see Barrett et al, 2004b).

\section{Population sampling for morphological and demographic measurements}

In 2003 and 2004, we sampled 76 populations (37 dimorphic and 39 trimorphic) in central Portugal and NW Spain recording latitude and longitude at each site. Localities for all populations are available from the first author on request. In each population, we estimated the style morph ratio (see Barrett et al, 2004b) and population size. Populations were identifiable as discrete colonies of plants separated from other populations usually by several kilometres. Two separate counts were made and the average was taken as the final estimate of population size. $N$. triandrus does not propagate clonally so the sampling of genets is unambiguous. In 58 populations (21 dimorphic and 37 trimorphic) plant height was measured from a random sample of individuals ( mean $=30.71$ individuals, range $=7-79$ individuals) and in 37 populations (13 dimorphic and 24 trimorphic) we also measured perianth length and flower number (mean $=95.8$ individuals, range $=14-224$ individuals). We determined near neighbour distances in 22 of these populations (eight dimorphic and 14 trimorphic) by randomly selecting focal individuals and measuring the distance from these individuals to their three closest neighbours. We previously established that this measure of density is closely correlated with counts of the numbers of individuals per square meter (unpublished data). The number of focal individuals used for density measurements varied depending on population size as the number of focal individuals was limited in small populations $($ mean $=37.4$, range $=13-46)$.

We used ANCOVA to determine the association between sexual system (trimorphic vs dimorphic), plant height, flower size and flower number (Glm procedure ver. 8.2 SAS Institute, 2001). The analysis was conducted using population means. We treated sexual system as a fixed effect and latitude as a covariate as both flower size and number increase with latitude (Barrett et al, 2004b). To test for significant differences in population size and near neighbour distance between dimorphic and trimorphic populations we used ANOVA (Glm procedure ver. 8.2, SAS Institute, 2001). When appropriate, we transformed data (eg log or square root) to meet the assumptions of statistical tests. In these cases least squared means and standard errors were back-transformed for presentation in figures.

\section{Estimates of mating patterns}

To estimate population mean and morph-specific maternal outcrossing rates, we collected seed families from a total of nine populations (five dimorphic, four trimorphic) during April and May 2004. Individuals were collected from populations with a minimum of 15 seed families per morph to achieve sufficient sample sizes for morph-specific estimates. Therefore, populations do not represent the entire range of morph frequencies or population sizes found in $N$. triandrus. The mean number of families per style morph sampled was 27.8 (range $=16-36)$. From each seed family, we assayed eight 
to ten seeds. For one dimorphic population, the number of families for the S-morph with a sufficient number of seeds was very low, so we estimated the outcrossing rate of the L-morph only.

We performed horizontal starch gel electrophoresis following the methods outlined in Barrett et al (1997). We crushed seeds in a small amount of $0.02 \mathrm{M} \mathrm{Na}_{2} \mathrm{HPO}_{4}$ buffer ( $\mathrm{pH} 7.4)$ containing DL-dithiothreitol $(1 \mathrm{mg} / \mathrm{ml})$. Chromatography paper wicks (Whatman $3 \mathrm{~mm}$ ) were used to absorb the resulting homogenate. The wicks were then inserted into 12-14\% starch gels. We stained gels for enzymes using the methods of Wendel and Weeden (1991). We initially screened 18 enzyme systems and from these three polymorphic loci were reliably resolved. A histidine-citrate buffer ( $\mathrm{pH}$ 6.5) was used to resolve phosphoglucomutase (PGM-1) and phosphoglucose isomerase (PGI-1) and a lithium borate buffer ( $\mathrm{pH} 8.3$ ) was used to resolve aspartate aminotransferase (AAT-2). We detected three alleles at the $A A T-2$ locus, four alleles at PGM-1 and six alleles at the PGI-1 locus.

We used Ritland's MLTR program for windows version 3.0, September 2004, available at http://genetics. forestryubc.ca/ritland/programs.html (see also Ritland, 1990b) to estimate multi- and single-locus maternal outcrossing rates as well as parental inbreeding coefficients. This program uses maximum likelihood procedures to infer the genotypes of the maternal parents, the allele frequencies of the pollen pool and the proportion of progeny that result from outcrossing $(t)$. Parental inbreeding coefficients $(F)$ are estimated from the inferred maternal genotype frequencies. The program assumes that allele frequencies do not differ significantly among morphs. If there are chance associations of the marker alleles with respect to the style morphs there will be a downward bias in $t$ when a common pollen pool is used to estimate the outcrossing rate rather than separate pollen pools. As trial runs indicated that there were significant differences in allele frequencies among the morphs at some loci, outcrossing rates were estimated using separate pollen pools (Eckert and Barrett, 1994; Baker et al, 2000). We derived SE of the outcrossing rates from 1000 bootstraps using the seed family as the unit of resampling.

Significant differences in outcrossing rate between the style morphs in populations were assessed by pairwise comparisons of 1000 bootstrap estimates following the methods of Eckert and Barrett (1994). Pairwise differences between the 1000 bootstrap estimates for each morph were calculated as $t_{i}-t_{j}$ (where $t_{i}$ and $t_{j}$ represent the bootstrap estimates for the $i$ th and $j$ th morph). With this approach, morphs were considered to be significantly different if $100\left(1-\alpha_{\mathrm{pc}} / 2\right)$ percentage of the differences between paired bootstrap values were either all greater than zero or all less than zero, where $\alpha_{p c}$ represents the type-I error rate per contrast. Similarly, we calculated overall differences among morphs and between dimorphic and trimorphic populations by determining the average of the L-, M- and S-morph $t_{\mathrm{m}}$ for a given bootstrap. Morphs or populations were considered to be significantly different when, as above, $100\left(1-\alpha_{\mathrm{pc}} / 2\right)$ percentage of the differences between paired bootstraps were either all greater than zero or all less than zero. Type-I error rate was calculated as $\alpha_{\mathrm{pc}}=1-(1-0.05)^{1 / \mathrm{C}}$ where $C$ represents the number of multiple contrasts (Sidák, 1967).
We calculated estimates of biparental inbreeding $\left(s_{\mathrm{s}}-s_{\mathrm{m}}\right)$ where $s_{\mathrm{s}}$ is the single-locus selfing rate and $s_{\mathrm{m}}$ is the multi-locus selfing rate (Ritland, 2002). These estimates are useful in comparisons among populations of the same species when the same set of loci are used (Lu, 2000; Ritland, 2002). However, we note that experimental estimates of biparental inbreeding indicate that this method may underestimate the true level of biparental inbreeding experienced in populations (Griffin and Eckert, 2003). We measured inbreeding depression ( $\delta=1$-fitness of selfed progeny/fitness of outcroseed progeny) for survival from seed to reproductive maturity from the multi-locus estimates of outcrossing rate $(t)$ and parental inbreeding $(F)$ using the equilibrium estimator of Ritland (1990a).

$$
\delta=1-\left[\frac{2 t F}{(1-t)(1-F)}\right]
$$

To determine significant differences, we examined the distributions of bootstrap values for each parameter $\left(s_{\mathrm{s}}-s_{\mathrm{m}}, F, \delta\right)$ in an analogous way to the method described for outcrossing rates. Values of $s_{\mathrm{s}}-s_{\mathrm{m}}$ and $F$ in which the confidence interval overlapped with 0 were considered not significantly different from 0 . Similarly, values of $\delta$ where the confidence interval overlapped with 1 were not significantly different from 1 .

We employed ANCOVA (JMP ver. 4.0 SAS Institute, 2000) to evaluate the extent to which variation in population size, near neighbour distance and sexual system were associated with variation in outcrossing rate. Sexual system was treated as a fixed effect and both population size and near neighbour distance were incorporated as covariates. Population size was log transformed. Any nonsignificant interactions of the covariates with sexual system were removed using backwards elimination. We weighted the outcrossing estimates by the inverse of their squared SE to take into account sampling errors associated with the estimates. Estimates of biparental inbreeding were analyzed in the same manner.

\section{Results}

\section{Demographic and morphological characteristics of dimorphic and trimorphic populations}

Dimorphic and trimorphic populations of $N$. triandrus differ significantly in demographic characteristics (Figure $1 \mathrm{a}$ and $\mathrm{b}$ ). Mean population size was significantly smaller in dimorphic populations compared to trimorphic populations $\left(F_{1,74}=16.49, P=0.0001\right)$. In addition, average distance to the nearest three neighbours was found to be significantly greater in dimorphic compared to trimorphic populations $\left(F_{1,20}=4.46\right.$, $P=0.047)$ as was the distance to the first, second and third nearest neighbours $\left(F_{1,20}=10.25, P=0.0045 ; F_{1,20}=\right.$ 8.02, $\left.P=0.0103 ; F_{1,20}=12.16, P=0.0023\right)$.

In testing for associations between morphological characteristics and sexual system, ANCOVAs revealed no significant interaction between sexual system and latitude and were removed from the model (Table 1). Plants in dimorphic populations were found to be significantly taller than plants in trimorphic populations $\left(F_{1,55}=15.85, P=0.0002\right.$; Figure $\left.1 c\right)$. Latitude also explained a significant proportion of the variation in plant 

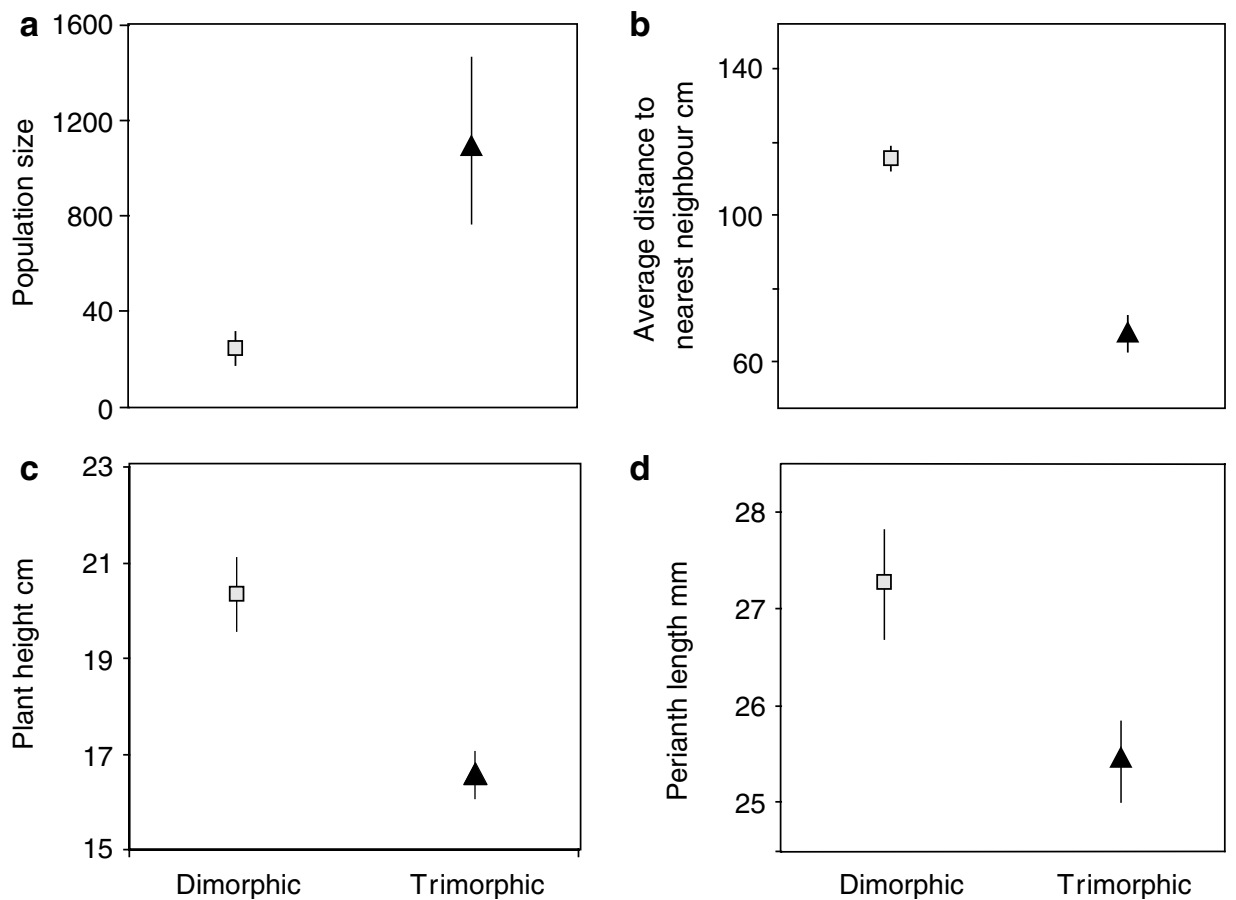

Figure 1 Demographic and morphological characteristics of dimorphic and trimorphic populations of $N$. triandrus var. triandrus. (a) The association between log population size and sexual system. (b) The association between the average distance of focal individuals to their three nearest neighbours and sexual system. (c) The association between the average plant height of populations and sexual system. (d) The association between the average perianth length of populations and sexual system. Means are shown \pm 1 SE.

Table 1 ANCOVA of three morphological characters among dimorphic and trimorphic populations of Narcissus triandrus

\begin{tabular}{llrl}
\hline Morphological trait & Source & F & P-value \\
\hline Plant height & Sexual system & $15.85(1,55)$ & 0.0002 \\
& Latitude & $4.09(1,55)$ & 0.048 \\
Perianth length & Sexual system & $19.28(1,34)$ & 0.041 \\
& Latitude & $1.19(1,34)$ & 0.283 \\
& & & \\
Flower number & Sexual system & $0.01(1,34)$ & 0.972 \\
& Latitude & $5.48(1,34)$ & 0.025 \\
\hline
\end{tabular}

Sexual system is a fixed effect and latitude a covariate. Degrees of freedom are indicated in parentheses.

height $\left(F_{1,55}=4.09, P=0.048\right)$. Perianth length was found to be significantly greater in dimorphic populations compared to trimorphic populations $\left(F_{1,34}=19.28\right.$, $P=0.041$; Figure 1d). The covariate latitude did not explain a significant proportion of the variation in perianth length $\left(F_{1,34}=1.19, P=0.283\right)$. Conversely, latitude was found to be significantly associated with flower number $\left(F_{1,34}=5.48, P=0.025\right)$ but sexual system was $\operatorname{not}\left(F_{1,34}=0.01, P=0.972\right)$.

\section{Mating patterns}

Outcrossing rates: There was a marginal difference in outcrossing rates between the two sexual systems of N. triandrus. Dimorphic populations exhibited slightly higher outcrossing rates than trimorphic populations $\left(t_{\mathrm{m}}\right.$ dimorphic $=0.759 \pm 0.0272, t_{\mathrm{m}}$ trimorphic $=0.710 \pm$ 0.0195 , proportion of $\left.t_{\mathrm{di}}-t_{\mathrm{tri}}<0=0.060\right)$. However, morph-specific estimates within dimorphic and trimorphic populations revealed no large or consistent differences among the style morphs (Figure $2 a$ and $b$ ). Of the eight populations examined, in only one (population 222 - dimorphic) was there a significant difference between the style morphs with the L-morph exhibiting a significantly higher outcrossing rate than the S-morph $\left(t_{\mathrm{m}}\right.$ long $=0.919 \pm 0.068, t_{\mathrm{m}}$ short $=0.536 \pm 0.0749$, proportion of $t_{1}-t_{\mathrm{s}}<0=0.000$ ). In dimorphic population 246 there was a trend towards significance although the direction of the effect was reversed with the L-morph with a lower outcrossing rate compared to the S-morph $\left(t_{\mathrm{m}}\right.$ long $=0.795 \pm 0.0518, \quad t_{\mathrm{m}}$ short $=0.930 \pm 0.0408$, proportion of $\left.t_{1}-t_{\mathrm{s}}>0=0.024\right)$. When morph-specific outcrossing rates among all dimorphic populations were compared, there was a significantly higher outcrossing rate in the L-morph compared to the Smorph $\left(t_{\mathrm{m}}\right.$ long $=0.801 \pm 0.0264, t_{\mathrm{m}}$ short $=0.710 \pm 0.0342$, proportion of $\left.t_{1}-t_{\mathrm{s}}<0=0.017\right)$. However, a single population was responsible for this difference and when it was removed from the analysis this difference was lost (proportion of $t_{1}-t_{\mathrm{s}}<0=0.314$ ).

There were no significant differences in outcrossing rates among the style morphs in trimorphic populations after correcting for multiple comparisons (Figure $2 b$ ). However, there was a trend towards significance in two instances. In population 276 the M-morph had a higher outcrossing rate than the L-morph $\left(t_{\mathrm{m}}\right.$ long $=$ $0.541 \pm 0.0647, t_{\mathrm{m}}$ mid $=0.719 \pm 0.0809$, proportion of $\left.t_{1}-t_{\mathrm{m}}>0=0.034\right)$ and in population 205 the M-morph had a lower outcrossing rate than the L-morph $\left(t_{\mathrm{m}}\right.$ long $=0.914 \pm 0.0444, t_{\mathrm{m}}$ mid $=0.747 \pm 0.0464$, proportion of $t_{1}-t_{\mathrm{m}}<0=0.012$ ). Interestingly, this occurred in populations with the highest (population $276=0.432$ ) 

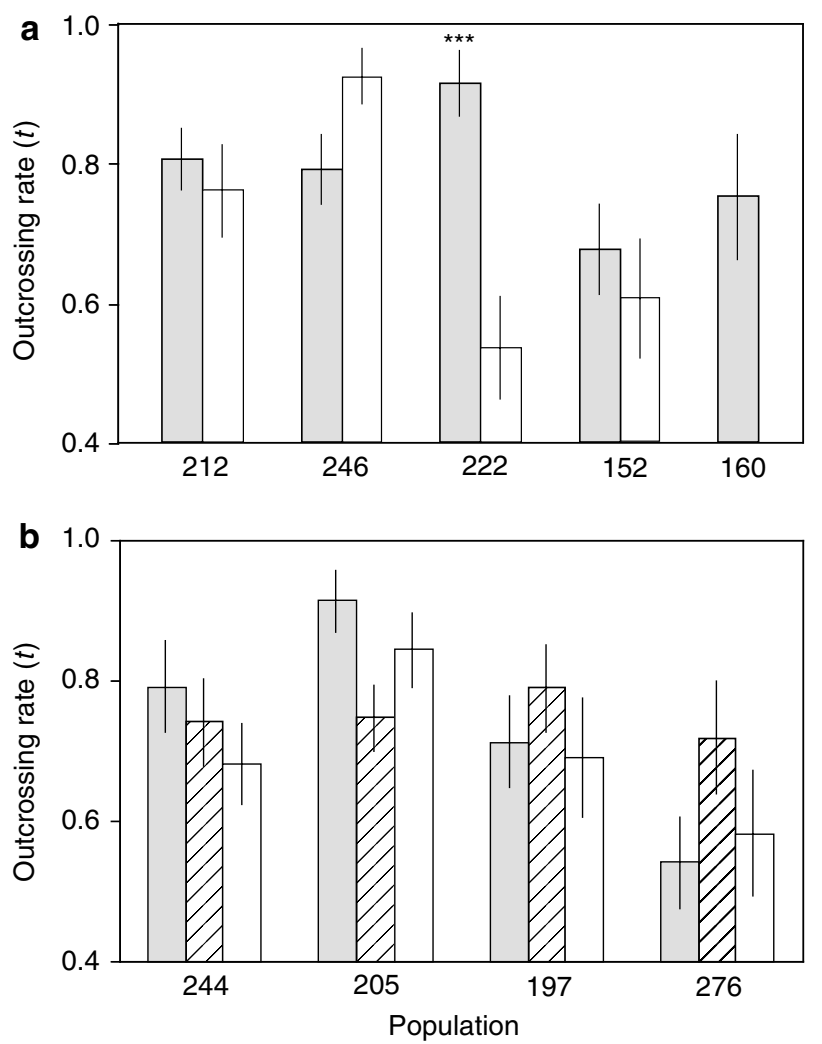

Figure 2 Estimated multi-locus outcrossing rates $(t)$ in nine populations of N. triandrus var. triandrus. Morph-specific estimates were obtained using separate pollen pools in Ritland's (1990a) MLTR program and error bars are standard errors based on 1000 bootstrap estimates. (a) Outcrossing rates of the L- and S-morphs in four dimorphic populations $(* * P<0.0001)$. For one dimorphic population (population 160) an outcrossing rate was estimated for only the L-morph. (b) Outcrossing rates of the L-, M- and S-morphs in four trimorphic populations. L-morph $=$ filled bars, $\mathrm{M}$-morph $=$ cross-hatched bars and S-morph $=$ open bars.

and lowest frequencies of the M-morph (population $205=0.174)$. When morph-specific differences among all trimorphic populations were compared no significant differences were evident $\left(t_{\mathrm{m}}\right.$ long $=0.740 \pm 0.0305, t_{\mathrm{m}}$ $\operatorname{mid}=0.749 \pm 0.0319, t_{\mathrm{m}}$ short $\left.=0.670 \pm 0.0363\right)$.

Biparental inbreeding: Population estimates of biparental inbreeding in $N$. triandrus were significantly different from 0 in all but one population (population 160 - dimorphic). Morph-specific estimates of biparental inbreeding revealed no significant differences among the style morphs within populations. Among all dimorphic populations there were no significant differences among morphs in biparental inbreeding $\left(s_{\mathrm{s}}-s_{\mathrm{m}}\right.$ long= $0.0865 \pm 0.0129, s_{\mathrm{s}}-s_{\mathrm{m}}$ short $\left.=0.0715 \pm 0.0116\right)$. Similarly, in trimorphic populations there were also no significant differences among the morphs $\left(s_{\mathrm{s}}-s_{\mathrm{m}}\right.$ long $=0.108 \pm$ $0.0121, s_{\mathrm{s}}-s_{\mathrm{m}} \mathrm{mid}=0.099 \pm 0.0112, s_{\mathrm{s}}-s_{\mathrm{m}}$ short $=0.096 \pm$ 0.0112). However, comparison of the two sexual systems revealed a significant difference in biparental inbreeding between dimorphic and trimorphic populations $\left(s_{\mathrm{s}}-s_{\mathrm{m}}\right.$ dimorphic $=0.102 \pm 0.0068, \quad s_{\mathrm{s}}-S_{\mathrm{m}} \quad$ trimorphic $=0.0646 \pm$ 0.0085 , proportion of $\left.\left(s_{\mathrm{s}}-s_{\mathrm{m}}\right)_{\mathrm{di}}-\left(s_{\mathrm{s}}-s_{\mathrm{m}}\right)_{\mathrm{tri}}<0=0.001\right)$.

Inbreeding depression: Not unexpectedly, given the observed selfing and biparental inbreeding, there was evidence of significant inbreeding, in progeny (mean $F=0.143$, range $=0.066-0.261$ ). However, by contrast parental inbreeding estimates were not significantly different from zero in eight out of the nine populations investigated (mean $F=0.062$, range $=-0.027-0.252$ ). This indicates that few inbred offspring survive to reproductive maturity due to strong inbreeding depression (Figure 3).

Demography and mating patterns: The effects of population size and density on outcrossing rate were first examined independently (Table 2). There was no relation between maternal outcrossing rates and population size in $N$. triandrus $(b \pm \mathrm{SE}=-0.0079 \pm$ $\left.0.0192, t_{7}=-0.41, \quad P=0.6929, \quad R^{2}=0.023\right)$. However, ANCOVA revealed a significant interaction between average near neighbour distance and sexual system $\left(F_{1,5}=6.801, P=0.0478\right)$. Therefore, outcrossing rates were regressed against average near neighbour distances separately for each sexual system. For dimorphic populations, there was a significant association between outcrossing rate and average near neighbour distance $\left(b \pm \mathrm{SE}=-0.0025 \pm 0.0007, \quad t_{3}=-3.78, \quad P=0.0324, \quad R^{2}=\right.$ 0.826; Figure 4a). Trimorphic populations had a significant association between outcrossing rate and average near neighbour distance $(b \pm \mathrm{SE}=-0.0073 \pm$ $\left.0.0016, t_{2}=-4.67, \quad P=0.0430, R^{2}=0.9158\right)$. Similarly, univariate analysis revealed that population size was not correlated with population estimates of biparental inbreeding $\left(b \pm \mathrm{SE}=-0.0085 \pm 0.0068, t_{7}=1.25, P=0.2514\right.$, $R^{2}=0.183$ ). However, average near neighbour distance was significantly associated with estimates of biparental inbreeding $\left(b \pm \mathrm{SE}=-0.0005 \pm 0.0002, t_{7}=-2.83, \quad P=\right.$ $0.0253, R^{2}=0.534$; Figure $4 \mathrm{~b}$ ). 
Table 2 Correlations between outcrossing rates, biparental inbreeding and demographic characteristics among nine Narcissus triandrus populations

\begin{tabular}{|c|c|c|c|c|}
\hline Mating system trait & Demographic trait & $\mathrm{t}$ & $\mathrm{R}^{2}$ & P-value \\
\hline Outcrossing rate & Population size & $-0.41(7)$ & 0.023 & 0.6929 \\
\hline Outcrossing rate (dimorphic populations) & Average distance to near neighbours & $-3.78(3)$ & 0.826 & 0.0324 \\
\hline Outcrossing rate (trimorphic populations) & Average distance to near neighbours & $-4.67(2)$ & 0.916 & 0.0430 \\
\hline Biparental inbreeding & Population size & $1.25(7)$ & 0.183 & 0.2514 \\
\hline Biparental inbreeding & Average distance to near neighbours & $-2.83(7)$ & 0.534 & 0.0235 \\
\hline
\end{tabular}

Degrees of freedom are indicated in parentheses.
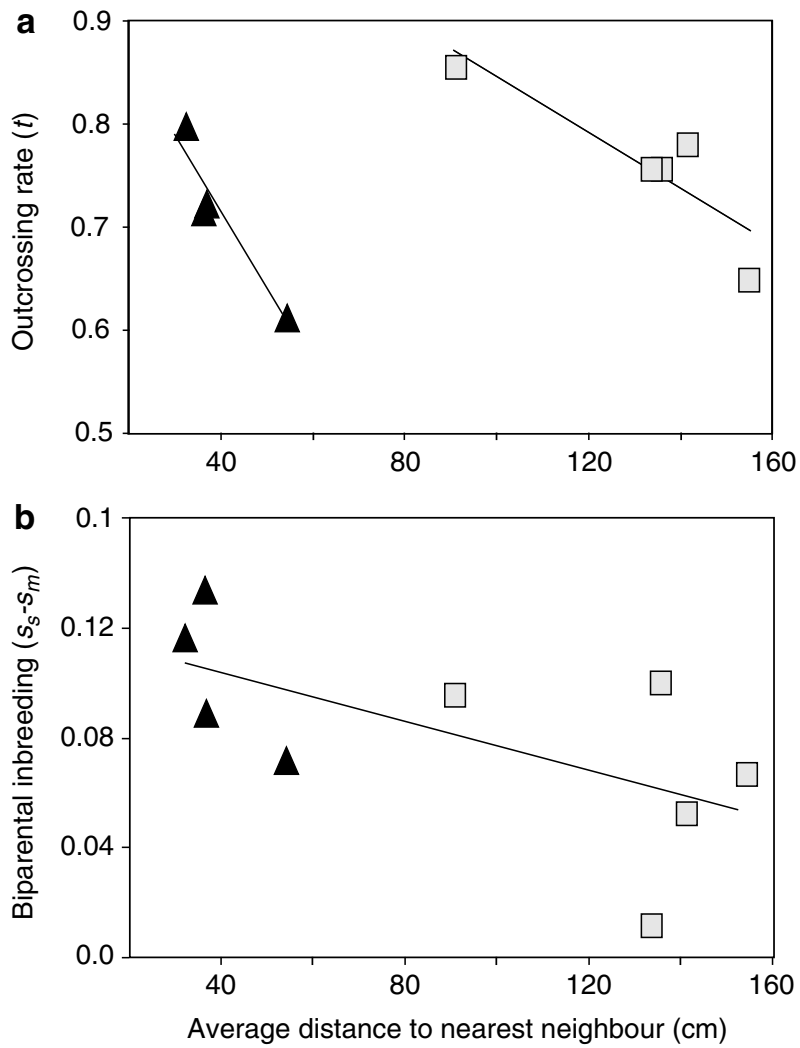

Figure 4 The correlation between inbreeding and density in nine populations of $N$. triandrus var. triandrus. (a) The association between outcrossing rate $(t)$ and average near neighbour distance in dimorphic and trimorphic populations. (b) The association between biparental inbreeding $\left(s_{\mathrm{s}}-s_{\mathrm{m}}\right)$ and average near neighbour distance. Triangles indicate trimorphic populations and squares dimorphic populations.

ANCOVA of outcrossing rate against density, population size and sexual system identified a significant effect of sexual system $\left(F_{1,5}=52.32, P=0.0008\right)$. There was an inverse relationship between outcrossing rate and near neighbour distance (partial regression coefficient $\pm \mathrm{SE}=$ $\left.-0.0007 \pm 0.0003, t_{5}=-6.12, P=0.0017\right)$, but a positive relationship between outcrossing rate and population size (partial regression coefficient $\pm S E=0.0377 \pm 0.0121$, $\left.t_{5}=-3.13, P=0.0259\right)$. All interactions were nonsignificant and removed from the model. For biparental inbreeding, multiple regression analysis revealed that biparental inbreeding was not associated with population size (partial regression coefficient $\pm S E=-0.0051 \pm$ $\left.0.0080, t_{6}=-0.64, P=0.5449\right)$ but was marginally nega- tively associated with near neighbour distance (partial regression coefficient $\pm S E=-0.0007 \pm 0.0003, t_{6}=-2.29$, $P=0.0617)$.

\section{Discussion}

With the advent of genetic markers, mating patterns are now routinely measured in plant populations and a considerable database now exists for outcrossing rate variation in flowering plants (Barrett and Eckert, 1990; Vogler and Kalisz, 2001). Most estimates of outcrossing have been obtained for self-compatible species, presumably because of the assumption that self-incompatible species experience limited variation in mating patterns. Previous work on $N$. triandrus indicates that the lateacting self-incompatibility system in this species is weakly expressed and significant levels of selfing can occur under field conditions (Barrett et al, 1997; Sage et al, 1999). A major goal of this study was, therefore, to investigate the role that demographic and morphological factors might play in influencing mating patterns and to evaluate the hypothesis that morph-specific differences in selfing could play a role in sexual-system evolution.

\section{Demographic and morphological characteristics of dimorphic and trimorphic populations}

We investigated demographic and morphological differences between dimorphic and trimorphic populations of $N$. triandrus. Our study revealed that populations with these contrasting sexual systems differ significantly in size, density, plant size and flower size (Figure 1). Dimorphic populations were smaller in size and on average had greater near neighbour distances compared to trimorphic populations. Dimorphic populations also have significantly larger plants that possess larger flowers than trimorphic populations, although a difference in flower number between the two sexual systems was not evident. In other plant species these demographic and floral characters are often associated with variation in mating patterns (see Table 1, Barrett and Eckert, 1990), we were therefore interested in determining to what extent this also occurs in N. triandrus.

\section{Mating patterns and morph loss in $N$. triandrus}

Our estimates of mating patterns in nine populations of $N$. triandrus var. triandrus indicated that this taxon is largely outcrossing. The average outcrossing rate was 0.74 (range $=0.61-0.86$ ) with only a small (5\%) mean difference between dimorphic and trimorphic populations. Significant amounts of selfing were, however, detected in all of the populations that we investigated. 
Our earlier estimates of outcrossing rates in N. triandrus involved four trimorphic populations of var. cernuus from southern and central Spain (mean $t_{\mathrm{m}}=0.77$, range $=0.68-0.87$, Barrett et al, 1997). Estimates from these two studies are therefore quite similar. Populations of var. cernuus are exclusively trimorphic whereas populations of var. triandrus are either dimorphic or trimorphic. Hence, there is no obvious indication from these population-level estimates that outcrossing-rate variation plays a significant role in the maintenance or loss of stylar trimorphism.

Morph-specific differences in selfing rate within tristylous populations can be an important factor in the evolution of morph ratios and in the destabilization of tristyly (Charlesworth, 1979; Weller 1992; Barrett, 1993). For example, Charlesworth's (1979) model concerning the breakdown of tristyly predicts that the M-morph is likely to experience higher selfing rates and indeed there is empirical evidence that supports this idea (Kohn and Barrett, 1992). If inbreeding depression is low, higher selfing in the M-morph can lead to its fixation in populations or, conversely, if inbreeding depression is severe the M-morph can decrease in frequency and be lost from populations (Charlesworth, 1979). Morphological and theoretical evidence indicate that contemporary dimorphic populations of $N$. triandrus are likely to be derived from trimorphic populations through loss of the M-morph (Barrett et al, 2004b). Therefore, consistently higher selfing rates in the M-morph of $N$. triandrus var. triandrus could provide a mechanism responsible for the origin of dimorphic populations.

Our results provided no clear support for the hypothesis that differences in the levels of self-fertilization among the morphs are responsible for biased morph ratios and the morph loss that characterizes populations of $N$. triandrus. Our genetic estimates of inbreeding depression were uniformly high in all but one population. Consequently, differences in selfing rates among the morphs could potentially lead to the decline and loss of the most highly selfing morph through viability and fertility selection. However, there were no consistent differences in outcrossing rate among the morphs that can easily explain either morph-ratio bias or morph loss from populations. Although there was a general lack of consistency in levels of outcrossing among morphs, several populations exhibited morph-specific differences in selfing, although in only one population were these differences statistically significant (Figure 2). This could indicate that the necessary conditions for morph loss occur only rarely. For example, in population 205 the selfing rate of the M-morph was $16 \%$ higher than the L-morph and in this population the M-morph was at a low frequency $(0.17)$. It is probable that the circumstances that lead to morph loss in $N$. triandrus var. triandrus are locally determined and that in this particular population continued selfing of the M-morph could conceivably result in its loss from the population.

Although the evidence that self-fertilization is involved in the loss of the M-morph from populations of $N$. triandrus is weak at best, self-pollination in Narcissus species has other detrimental consequences in addition to inbreeding depression. $N$. triandrus possesses an ovarian self-incompatibility system in which self pollen tube growth causes the arrest of developing ovules prior to fertilization, a phenomenon known as ovule discount- ing (Barrett et al, 1996). Pollination studies have revealed that prior or simultaneous self-pollination results in reduced seed set (Sage et al, 1999). Future work on morph-specific estimates of self-pollination and ovule discounting are required to evaluate whether differences in levels of self-pollination among the style morphs may be contributing to the origin of dimorphic populations from trimorphic populations.

\section{Mating and population structure}

Single-locus estimates of outcrossing rate were significantly lower than multi-locus estimates in eight out of the nine populations of $N$. triandrus. This provides evidence for biparental inbreeding probably as a result of spatial genetic subdivision within populations. Seeds of this species have no obvious dispersal mechanisms and simply fall in the vicinity of maternal parents when capsules dehisce. Owing to the diminutive stature of the plants this likely results in relatively restricted seed dispersal. Spatial structure is expected to develop in populations with limited seed dispersal and local pollinator foraging. These features would enhance opportunities for mating among relatives. Although biparental inbreeding appears to be a pervasive feature of $N$. triandrus populations we found no evidence that the style morphs differ in this component of inbreeding, or that it is involved with transitions between trimorphism to dimorphism.

We detected a positive association between plant density and biparental inbreeding in populations of N. triandrus (Figure $4 \mathrm{~b}$ ). In dense populations, pollinator behaviour in conjunction with restricted seed dispersal can often result in local biparental inbreeding. Positive associations between biparental inbreeding and plant density have been reported in the self-incompatible Phlox drummondii (Watkins and Levin, 1990) and bird-pollinated Banksia cuneata (Coates and Sokolowski, 1992). Our analysis of biparental inbreeding also revealed an association with sexual system. Dimorphic populations despite being smaller in size engaged in significantly less biparental inbreeding than trimorphic populations. The lower biparental inbreeding levels may reflect greater seed dispersal distances caused by the greater height of dimorphic plants compared to trimorphic plants (Figure 1c). However, this pattern could also reflect the observed differences in density of dimorphic and trimorphic populations (Figure 1b). Pollinator foraging in low density populations has been shown to result in fewer visits to near neighbours thus reducing the incidence of mating among relatives (Levin and Kerster, 1969a, b; Kameyama et al, 2002; Degen et al, 2004). The proximate ecological mechanisms that cause differences in density between trimorphic and dimorphic populations are unknown but may be associated with extent of suitable habitat for seedling establishment.

Associations between mating patterns and population size have been demonstrated in several plant species (Raijmann et al, 1994; Routley et al, 1999), although this pattern does not always occur (vanTreuren et al, 1993; Barrett et al, 2004a; Zoro Bi et al, 2005). In Salvia pratensis population density, rather than population size was inversely related to selfing rate (vanTreuren et al, 1993). Our data revealed an association between near neighbour distances and outcrossing rate, as well as between 
population size and outcrossing rate, when the variation in density was controlled for statistically. Although trimorphic populations had higher plant densities and larger population sizes than dimorphic populations, selfing rates were marginally higher in trimorphic populations. This suggests that factors other than density and population size are affecting the mating system of dimorphic and trimorphic populations. These could include flower size variation (Rick et al, 1978) and differences in the types of pollinators visiting populations of the two sexual systems.

Our estimates of inbreeding in the progeny of $N$. triandrus indicate a significant deficit of heterozygotes. However, the analysis of parental genotypes revealed that they are largely the products of outcrossing. This indicates that selfed offspring of $N$. triandrus do not survive to reproductive maturity as a result of strong inbreeding depression. Indeed, in eight of the nine populations measurements of inbreeding depression were not significantly different from one. Genetic estimates of inbreeding depression in other plant species with mixed mating also indicate very low survival of selfed offspring in comparison with outcrossed offspring (Eckert and Barrett, 1994; Routley et al, 1999; Dorken et al, 2002; Barrett et al, 2004a; Medrano et al, 2005). Given the genetic costs of selfing in $N$. triandrus it seems unlikely that partial selfing is commonly adaptive in this species. Why leaky self-incompatibility is maintained in $N$. triandrus is therefore unclear.

\section{Acknowledgements}

We thank Lawrence Harder for valuable discussions, William Cole for technical advice, and Reagan Johnson for field assistance in collecting seeds. This work was funded by the Natural Sciences and Engineering Research Council of Canada through a discovery grant to SCHB and a postgraduate fellowship to KAH.

\section{References}

Ågren J (1996). Population size, pollinator limitation, and seed set in the self-incompatible herb Lythrum salicaria. Ecology 77: 1779-1790.

Baker AM, Thompson JD, Barrett SCH (2000). Evolution and maintenance of stigma-height dimorphism in Narcissus. II. Fitness comparisons between style morphs. Heredity 84: 514-524.

Barrett SCH (1993). The evolutionary biology of tristyly. In: Futuyma D, Antonovics J (eds) Oxford Surveys in Evolutionary Biology. Oxford University Press: Oxford. pp 283-326.

Barrett SCH, Cole WW, Arroyo J, Cruzan MB, Lloyd DG (1997). Sexual polymorphisms in Narcissus triandrus (Amaryllidaceae): is this species tristylous? Heredity 78: 135-145.

Barrett SCH, Cole WW, Herrera CM (2004a). Mating patterns and genetic diversity in the wild daffodil Narcissus longispathus (Amaryllidaceae). Heredity 92: 459-465.

Barrett SCH, Cruzan MB (1994). Incompatibility in heterostylous plants. In: Williams EG, Knox RB, Clark AE (eds) Genetic Control of Incompatibility and Reproductive Development in Flowering Plants. Kluwer Academic: The Netherlands. pp 189-219.

Barrett SCH, Eckert CG (1990). Variation and evolution of mating systems in seed plants. In: Kawano S (ed) Biological Approaches and Evolutionary Trends in Plants. Academic Press: London. pp 229-254.
Barrett SCH, Harder LD, Cole WW (2004b). Correlated evolution of floral morphology and mating-type frequencies in a sexually polymorphic plant. Evolution 58: 964-975.

Barrett SCH, Lloyd DG, Arroyo J (1996). Stylar polymorphisms and the evolution of heterostyly. In: Lloyd DG, Barrett SCH (eds) Floral Biology: Studies on Floral Evolution in AnimalPollinated Plants. Chapman \& Hall: New York. pp 339-376.

Blanchard JW (1990). Narcissus: A Guide to Wild Daffodils. Alpine Garden Society: Surrey, UK.

Charlesworth D (1979). The evolution and breakdown of tristyly. Evolution 33: 486-498.

Charlesworth D, Charlesworth B (1987). Inbreeding depression and its evolutionary consequences. Ann Rev Ecol Syst 18: 237-268.

Coates DJ, Sokolowski RES (1992). The mating system and patterns of genetic variation in Banksia cuneata A.S. George (Proteaceae). Heredity 69: 11-20.

Degen B, Bandou E, Caron H (2004). Limited pollen dispersal and biparental inbreeding in Symphonia globulifera in French Guiana. Heredity 93: 585-591.

Dorken ME, Friedman J, Barrett SCH (2002). The evolution and maintenance of monoecy and dioecy in Sagittaria latifolia (Alismataceae). Evolution 56: 31-41.

Eckert CG, Barrett SCH (1994). Postpollination mechanisms and the maintenance of outcrossing in self-compatible, tristylous, Decodon verticillatus (Lythraceae). Heredity 72: 396-411.

Fernandes A (1965). Contribution à la connaissance de la génétique de l'hétérostylie chez le genre Narcissus L. II. l'hétérostylie chez quelques populations de $N$. triandrus var cernuus et $N$. triandrus var. concolor. Genét Ibérica 17: 215-239.

Fisher RA (1941). The theoretical consequences of polyploid inheritance for the mid style form in Lythrum salicaria. Ann Eugen 11: 31-38

Fisher RA (1944). Allowance for double reduction in the calcualtion of genotype frequencies with polysomic inheritance. Ann Eugen 12: 169-171.

Griffin CAM, Eckert CG (2003). Experimental analysis of biparental inbreeding in a self-fertilizing plant. Evolution 57: 1513-1519.

Hamrick JL, Godt MJ (1989). Allozyme diversity in plant species. In: Brown AHD, Clegg MT, Kahler AL, Weir BS (eds) Plant Population Genetics, Breeding, and Genetic Resources. Sinauer: Sunderland, MA. pp 43-63.

Heuch I (1979). Equilibrium populations of heterostylous plants. Theor Popul Biol 15: 43-57.

Heywood JS (1991). Spatial analysis of genetic variation in plant populations. Ann Rev Ecol Syst 22: 335-355.

Holsinger KE (1996). Pollination biology and the evolution of mating systems in flowering plants. In: Hecht MK, Steere W, Wallace B (eds) Evolutionary Biology. Plenum Press: New York. pp 107-149.

Kalisz S, Nason JD, Hanzawa FM, Tonsor SJ (2001). Spatial population genetic structure in Trillium grandiflorum: the roles of dispersal, mating, history, and selection. Evolution 55: 1560-1568.

Kameyama Y, Isagi Y, Nakagoshi N (2002). Relatedness structure in Rhododendron metternichii var. hondoense revealed by microsatellite analysis. Mol Ecol 11: 519-527.

Kohn JR, Barrett SCH (1992). Experimental studies on the functional significance of heterostyly. Evolution 46: 43-55.

Levin DA, Kerster HW (1969a). Density-dependent gene dispersal in Liatris. Am Nat 103: 61-71.

Levin DA, Kerster HW (1969b). Dependence of bee-mediated pollen and gene dispersal upon plant density. Evolution 23 560-571.

Lloyd DG (1980). Demographic factors and mating patterns in angiosperms. In: Solbrig OT (ed) Demography and Evolution in Plant Populations. Blackwell: Oxford. pp 67-88.

Lu YQ (2000). Effects of density on mixed mating systems and reproduction in natural populations of Impatiens capensis. Int J Plant Sci 161: 671-681. 
Medrano M, Alonso C, Herrera CM (2005). Mating system, sex ratio, and persistence of females in the gynodioecious shrub Daphne laureola L. (Thymelaeaceae). Heredity 94: 37-43.

Moeller DA, Geber MA (2005). Ecological context of the evolution of self-pollination in Clarkia xantiana: population size, plant communities, and reproductive assurance. Evolution 59: 786-799.

Raijmann LEL, vanLeeuwen NC, Kersten R, Oostremeijer JGB, DenNijs HCM, Menken SBJ (1994). Genetic variation and outcrossing rate in relation to population size in Gentiana pneumonanthe. Cons Biol 8: 1014-1026.

Rick CM, Holle M, Thorp RW (1978). Rates of cross-pollination in Lycopersicon pimpinellifolium: impact of genetic variation in floral characters. Pl Syst Evol 129: 31-44.

Ritland K (1990a). Inferences about inbreeding depression based on changes of the inbreeding coefficient. Evolution 44: 1230-1241.

Ritland K (1990b). A series of Fortran computer programs for estimating plant mating systems. J Heredity 81: 235-237.

Ritland K (2002). Extensions of models for the estimation of mating systems using $n$ independent loci. Heredity 88: 221-228.

Routley MB, Mavraganis K, Eckert CG (1999). Effect of population size on the mating system in a self-compatible, autogamous plant, Aquilegia canadensis (Ranunculaceae). Heredity 82: 518-528.

Sage TL, Strumas F, Cole WW, Barrett SCH (1999). Differential ovule development following self- and cross-pollination: the basis of self-sterility in Narcissus triandrus (Amaryllidaceae). Am J Bot 86: 855-870.
SAS Institute (2000). Jmp Users Guide. 4.0. Sas Institute Inc.: Cary, NC.

SAS Institute (2001). Sas Onlinedoc. ver. 8.2. Sas Institute Inc.: Cary, NC.

Sidák Z (1967). Rectangular confidence regions for the means of multivariate normal distributions. J Am Stat Assoc 62: 626-633.

Sih A, Baltus M (1987). Patch size, pollinator behavior and pollinator limitation in catnip. Ecology 68: 1679-1690.

Turner ME, Stephens JC, Anderson WW (1982). Homozygosity and patch structure in plant populations as a result of nearest-neighbor pollination. Proc Natl Acad Sci-Biol 79: 203-207.

vanTreuren R, Bijlsma R, Ouborg NJ, vanDelden W (1993). The effects of population size and plant density on outcrossing rates in locally endangered Salvia pratensis. Evolution 47: 1094-1104.

Vogler DW, Kalisz S (2001). Sex among the flowers: the distribution of plant mating systems. Evolution 55: 202-204.

Watkins L, Levin DA (1990). Outcrossing rates as related to plant density in Phlox drummondii. Heredity 65: 81-89.

Weller SG (1992). Evolutionary modifications to tristylous breeding systems. In: Barrett SCH (ed) Evolution and Function of Heterostyly. Springer Verlag: Berlin. pp 247-272.

Wendel JF, Weeden NF (1991). Visualization and interpretation of plant isozymes. In: Soltis DE, Soltis PS (eds) Isozymes in Plant Biology. Dioscorides Press: Portland. pp 5-45.

Wright S (1943). Isolation by distance. Genetics 28: 114-138.

Zoro Bi I, Maquet A, Baudoin JP (2005). Mating system of wild Phaseolus lunatus L. and its relationship to population size. Heredity 94: 153-158. 